\title{
High-temperature Rheological Behavior and Numerical Simulation Technology for 6061 Aluminum Alloy Connecting Rods
}

\author{
Zhang Wei ${ }^{1, *}$ and Yu Yandong ${ }^{2}$ \\ ${ }^{1}$ Rongcheng College of Harbin University of Science and Technology, Rongcheng City, Shandong Province, 264300, China \\ ${ }^{2}$ Materials Science and Engineering Institute, Harbin University of Science and Technology, Harbin, Heilongjiang Province, 150040, \\ China
}

Received 25 September 2018; Accepted 12 December 2018

\begin{abstract}
Aluminum alloy connecting rods formed by common hot forging usually exhibit many surface defects, including cracks, folding, and disordered metal streamlines. These defects can considerably influence their performance. A thermosimulation compression experiment on 6061 aluminum alloy was conducted to prevent such defects and disclose the law of precise forging. The true stress- strain curves and stress peak under different deformation temperatures and strain rates were also obtained. The constitutive equation for the high-temperature rheological stress of 6061 aluminum alloy was derived. On the basis of this equation, the multi-field coupling problem of 6061 aluminum alloy connecting rods during closed forging deformation was discussed, and the influences of three forging techniques on forging results were analyzed. Results demonstrate that 6061 aluminum alloy is sensitive to positive strain rates. Steady-state flow stress is inversely proportional to temperature given a fixed strain rate, and flow stress is proportional to strain rate when the deformation temperature is fixed. During the closed forging process of aluminum alloy connecting rods, the upper and bottom punches move first, followed by the lateral punches, thereby resulting in a notable forging effect. Forging quality is inversely proportional to the movement order of lateral punches. In addition, the forging load of aluminum alloy connecting rods first increases and then decreases and finally increases. Forging load is proportional to deformation rate. The proposed method provides an excellent prospect to determine the closed forging technique of aluminum alloy.
\end{abstract}

Keywords: 6061 aluminum alloy, Connecting rods, Rheological behavior, Numerical simulation

\section{Introduction}

Aluminum alloy is extensively used in various fields owing to its considerable advantages, such as small density, high specific strength, and efficient processing. This material is lightweight and applicable to automobiles. At present, the demands for aluminum alloy forgings in the minicar part and all-purpose gasoline engine markets are dramatically increasing. In China, most small gasoline engine parts, such as connecting rods, rockers, various transmission shafts, and shifting forks, are made of high-strength aluminum alloy [1]. The traditional production technologies for aluminum alloy connecting rods are liquid forging, low-pressure casting, pressure casting, and cutting after common hot forging. However, the aluminum alloy connecting rods manufactured by casting exhibit many defects, such as poor surface smoothness, pores, and impurities in parts. The common hot forging shows many disadvantages, such as extensive production procedures, long technological process, low material utilization (only $50 \%-60 \%$ ), high production cost, and poor surface smoothness manifested in surface cracks, folds, and disordered metal streamline. Thus, developing a precise forging technology for aluminum alloy is necessary to achieve high-quality forgings with excellent size accuracy and smooth surface.

The 6061 aluminum alloy is a typical heat-deformable

*E-mail address: zhangw_hrbust@163.com

ISSN: $1791-2377$ @ 2018 Eastern Macedonia and Thrace Institute of Technology. All rights reserved.

doi:10.25103/jestr.116.15 alloy that demonstrates comprehensive performance. However, few systematic studies have explored the thermal deformation behavior of 6061 aluminum alloy. Accurately simulating and studying the forging process of 6061 aluminum alloy through numerical simulations are impossible because the material base and constitutive relationships are inaccurate in numerical simulation software. Aluminum alloy connecting rods are flat and long. This condition results in difficulties in forging and considerable challenges in the study of closed forging of aluminum alloy connecting rods [2-3].

Therefore, many numerical simulation studies on the rheological behavior of 6061 aluminum alloy and the precise forging of aluminum alloy have been reported [4-7]. Nevertheless, a multi-field coupling problem still exists during the hot deformation of aluminum alloy connecting rods, and the influences of hot deformation parameters on stress-strain field result in deviation from the actual process. Therefore, accurately predicting the relationship between forging mode and quality and defining the law of precise forging and the multi-field coupling relationship of aluminum alloy connecting rods are problems that need to be urgently solved.

On the basis of the above analysis, a finite element calculation model of the precise forging of aluminum alloy connecting rods was developed in the present study via experiments and the finite element method. The forging process, multi-field coupling characteristics, and load-stroke curve features of aluminum alloy connecting rods were 
analyzed. This study aims to accurately predict the relationship between forging mode and quality and provide references for the development and optimization of a precise forging process for aluminum alloy connecting rods.

\section{State of the art}

Scholars have reported studies on the precise forging of 6061 aluminum alloy connecting rods. Ma [8] designed a forging blank model and mold for 6061 aluminum alloy connecting rods and conducted a numerical simulation on the forging process by finite element analysis software. However, the author provided no deep discussion on the rheological behavior of 6061 aluminum alloy but directly applied the material using the software, thus resulting in deviations in the calculated results. Zhang [9] studied the multi-directional forging technology for high-strength connecting rods for small gasoline engines and designed a special hydraulic machine and closed forging testing device. However, the author hardly discussed the mechanism of closed forging. Zhang [10] discussed the forging technology for the aluminum alloy connecting rods of bikes on the basis of the open forging method and determined a reasonable forging process. However, the material utilization of open forging was low. $\mathrm{Wu}$ [11] analyzed the influences of prefabricated blank shape and size and forging method on the closed forging performance of aluminum alloy connecting rods and revealed the causes of forging defects on aluminum alloy connecting rods. However, the microstructural changes during the forging process were not studied. $\mathrm{Qu}[12]$ studied the evolutionary law of microstructures of $2 \mathrm{~A} 12$ aluminum alloy connecting rods during closed forging and determined a closed forging program, which was unverified by a test. Yao [13] conducted a numerical simulation of the pre-forging process under different loading modes of four forging devices for the engine connecting rods of automobiles. Moreover, the equivalent strain field, temperature field, and load changes during pre-forging with four devices were compared. However, the forging material applied was C70S6 steel. Huang [14] implemented a finite element numerical simulation of the multi-directional forging process and evolutionary law of microstructure of 6061 aluminum alloy. However, the limited parameters of the two technologies could not reflect the actual production. Balakrishna [15-16] conducted a comparative analysis of equal channel angular pressing, multi-directional forging, and accumulative rollbonding of 6061 aluminum alloy under room temperature. The authors found a similar variation trend in hardness and tensile properties, but the rheological behavior was not considerably influenced. The aluminum alloy still exhibited high sensitivity to strain rate after multi-directional forging, and such property was conducive to forging. However, the rheological behavior of the 6061 aluminum alloy at $350{ }^{\circ} \mathrm{C}-$ $500{ }^{\circ} \mathrm{C}$ was not extensively discussed. Lou [17] explored the rheological stress behavior of ultra-strong 7A09 aluminum alloy with a Gleeble-1500 thermal simulated compression testing machine and described the rheological behavior on the basis of the Zener-Hollomon constitutive model. However, no specific forging process was formed. Although Sitdikov [18] compared the structural evolutionary law and microstructural deformation mechanism of 7475 aluminum alloy under high-temperature, multi-directional, and unidirectional compression, the author did not thoroughly illustrate the production of forging defects. Khaleed [19-21] performed a numerical simulation of closed forging of \#45 steel connecting rods using three blanks with different shapes and concluded the optimal shape and dimension of blanks. However, the stress-strain field during the forging process was superficially discussed. Liu [22-25] not only reported a numerical simulation optimization analysis of the hot forging of connecting rods on the basis of response surface analysis with experimental verification but also analyzed parameter variables that influence forging loads and mold wearing. The analysis results were only limited to open forging.

The above-mentioned studies mainly focus on open and closed forging and mold optimization for connecting rods. However, the closed forging mechanism, microstructural changes of materials during the forging process, and rheological behavior of 6061 aluminum alloy during precise forging are hardly studied. In the present study, the rheological behavior of 6061 aluminum alloy under high temperature, material performance parameters, and constitutive relationship were disclosed on the basis of the Arrhenius hyperbolic sine equation by combining a thermal simulated compression test and numerical simulation. A finite element model of closed forging of aluminum alloy connecting rods was developed by using DEFFORM software as the simulation platform. The forging process, stress-strain field, speed field, and forging load were analyzed, thereby obtaining the optimal forging program, predicting the forging force, and evaluating forging quality. The results should provide references for the optimization and testing of precise forging of aluminum alloy connecting rods.

The remainder of this study is organized as follows. Section 3 analyzes the rheological behavior of 6061 aluminum alloy and establishes the constitutive relationship for high-temperature comprehensive rheological stress. Section 4 presents the numerical simulation analysis of closed forging of 6061 aluminum alloy connecting rods. Finally, Section 5 summarizes the conclusions.

\section{Methodology}

\subsection{Hot compressive test}

An orthogonal experiment was conducted, and the sample size was $\varphi 8 \times 12 \mathrm{~mm}$. The thermocouple was heated, and gaskets were added at two ends to decrease the error caused by friction force (Fig.1). The thermal compression experiment on the 6061 aluminum alloy samples was accomplished with a Gleeble-1500 thermal simulated compression testing machine (Fig.2). The parameters of the thermal compression experiment are listed in Table 1.

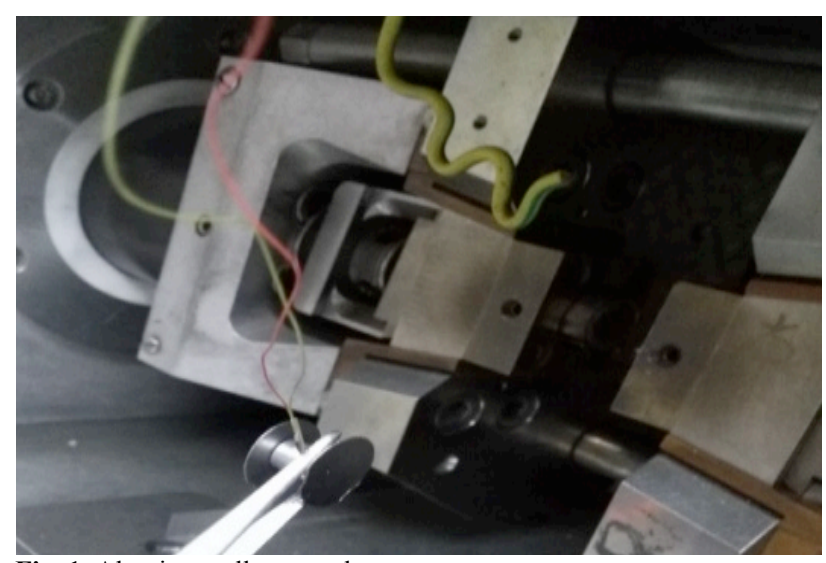

Fig. 1. Aluminum alloy samples 


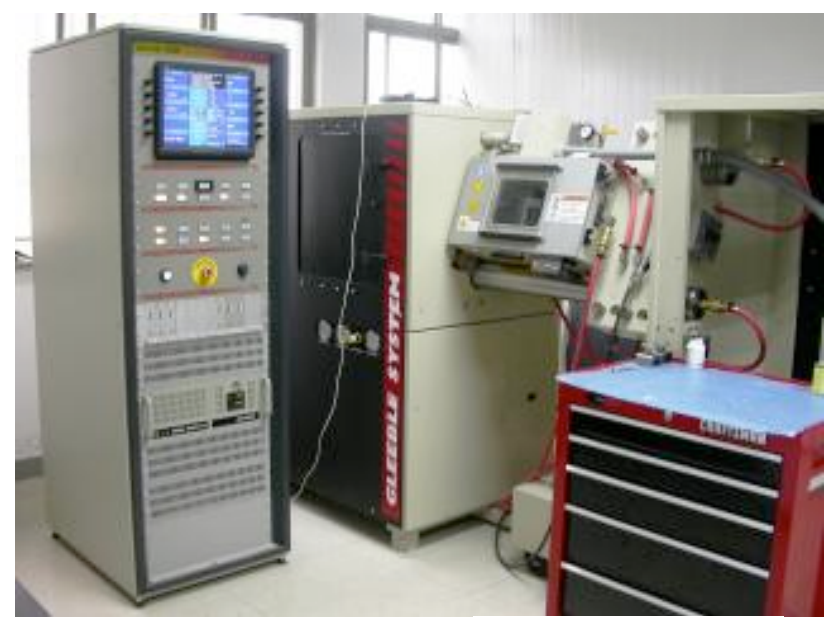

Fig. 2. Gleeble-1500 thermal simulated compression testing machine

Table 1. Parameters of thermal compression of aluminum alloy

\begin{tabular}{|c|c|c|c|}
\hline $\begin{array}{c}\text { Temperature } \\
{ }^{\circ} \mathrm{C}\end{array}$ & $\begin{array}{c}\text { Strain } \\
\text { rate } \\
s^{-1}\end{array}$ & $\begin{array}{c}\text { Original } \\
\text { diameter } \\
m m\end{array}$ & $\begin{array}{c}\text { Original height } \\
\mathrm{mm}\end{array}$ \\
\hline \multirow{4}{*}{350} & 0.01 & 8.06 & 12.04 \\
\hline & 0.1 & 8.07 & 12.02 \\
\hline & 1 & 8.06 & 12.03 \\
\hline & 5 & 8.07 & 12.02 \\
\hline \multirow{4}{*}{400} & 0.01 & 8.06 & 12.00 \\
\hline & 0.1 & 8.07 & 12.03 \\
\hline & 1 & 8.07 & 12.05 \\
\hline & 5 & 8.07 & 12.02 \\
\hline \multirow{4}{*}{450} & 0.01 & 8.07 & 12.03 \\
\hline & 0.1 & 8.06 & 12.05 \\
\hline & 1 & 8.07 & 12.04 \\
\hline & 5 & 8.05 & 12.06 \\
\hline \multirow{4}{*}{500} & 0.01 & 8.05 & 12.02 \\
\hline & 0.1 & 8.07 & 12.05 \\
\hline & 1 & 8.06 & 12.03 \\
\hline & 5 & 8.07 & 12.03 \\
\hline
\end{tabular}

\subsection{Physical model of the closed forging mold}

The closed forging mold of 6061 aluminum alloy was designed by using UG. This model was composed of upper and lower dies, two upper and two lower punches, and one lateral punch. Data were converted into STL format (Fig. 3).

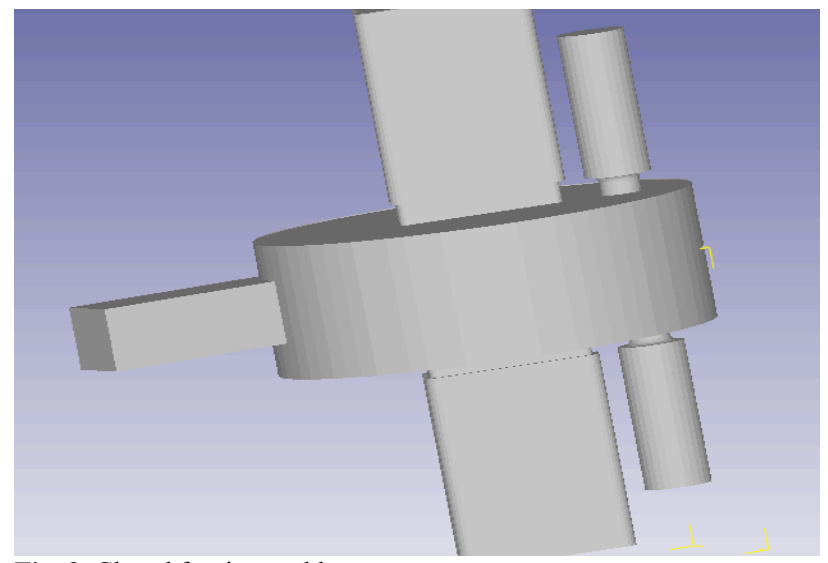

Fig. 3. Closed forging mold

\subsection{Finite element model}

The connecting rod blank was meshed by tetrahedron elements. The aspect ratio of the grids was 3, and the total number of grids was 35,000 , thereby meeting the requirements for calculation accuracy. The meshing diagram of a connecting rod blank is shown in Fig. 4.

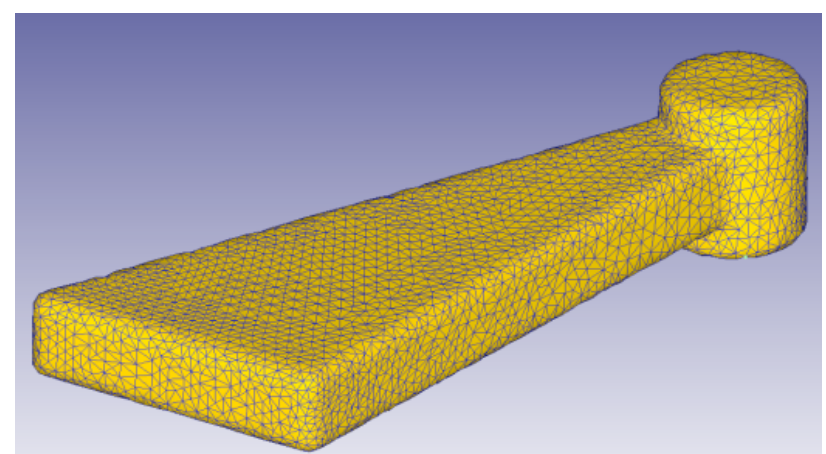

Fig. 4. Meshing program of connecting rod blank

\subsection{Material properties and computational boundaries}

AL6061 was chosen as the test material, and a plastomer was used as the blank. The friction model between the blank and the mold was a common shear friction model, and the mold was viewed as a rigid body. The friction factor was 0.3 . Given temperature changes, the initial temperature of the blank was $300{ }^{\circ} \mathrm{C}$, and that of the punches and mold was set to $200{ }^{\circ} \mathrm{C}$. The heat exchange coefficient between the mold and punch and the blank was $2 \mathrm{~kW} /\left(\mathrm{m} /{ }^{\circ} \mathrm{C}\right)$. The punch speed was set to $10 \mathrm{~mm} / \mathrm{s}$.

\subsection{Simulation program of closed forging}

The shape of 6061 aluminum alloy connecting rods is complicated. Three programs were designed for mold movement.

1). The big head is first formed, followed by the formation of the middle and small heads. Specifically, the lateral punch first moves, followed by the upper and lower punches.

2). The small head and middle part are first formed, and finally the big head is formed. Specifically, the upper and lower punches first move, followed by the lateral one.

3). Three parts of the connecting rod are simultaneously formed. Hence, the punches in three directions concurrently move.

\section{Result analysis and discussion}

The true stress-strain curves under different deformation temperatures and strain rates were obtained on the basis of the thermal compression experiment presented in Section 3.1 (Figs. 4 and 5). The stress peaks of 6061 aluminum alloy during high-temperature thermal compression under different deformation temperatures and strain rates are shown in Table 2.

As shown in Table 2 and Fig. 4, the flow stress decreases with an increase in deformation temperature given the fixed strain rate. This result is related to the increased movement of dislocation. As temperature rises, the thermal activation of materials is strengthened, and the average kinetic energy of metal atoms is increased, thereby augmenting the opportunity for crossing slippage and climbing of dislocations. Consequently, flow stress decreases. The major reasons are interpreted as follows.

(1) High deformation temperature strengthens the dynamic recovery and recrystallization softening of alloy during the deformation process and decreases rheological stress. The dynamic recovery and recrystallization occur in advance. 
(2) The critical shear stress of materials declines with an increase in deformation temperature, thereby increasing the number of slip systems. Accordingly, the rheological stress of aluminum alloy decreases.

(3) High deformation temperature is accompanied by a large thermoplasticity of materials and strong thermal vibration of atoms. The atom instability in a lattice is intensified, thereby decreasing the deformation resistance of metals.

As shown in Table 2 and Fig. 4, the flow stress decreases with an increase in deformation temperature given the fixed strain rate. This result is related to the increased movement of dislocation. As temperature rises, the thermal activation of materials is strengthened, and the average kinetic energy of metal atoms is increased, thereby augmenting the opportunity for crossing slippage and climbing of dislocations. Consequently, flow stress decreases. The major reasons are interpreted as follows.
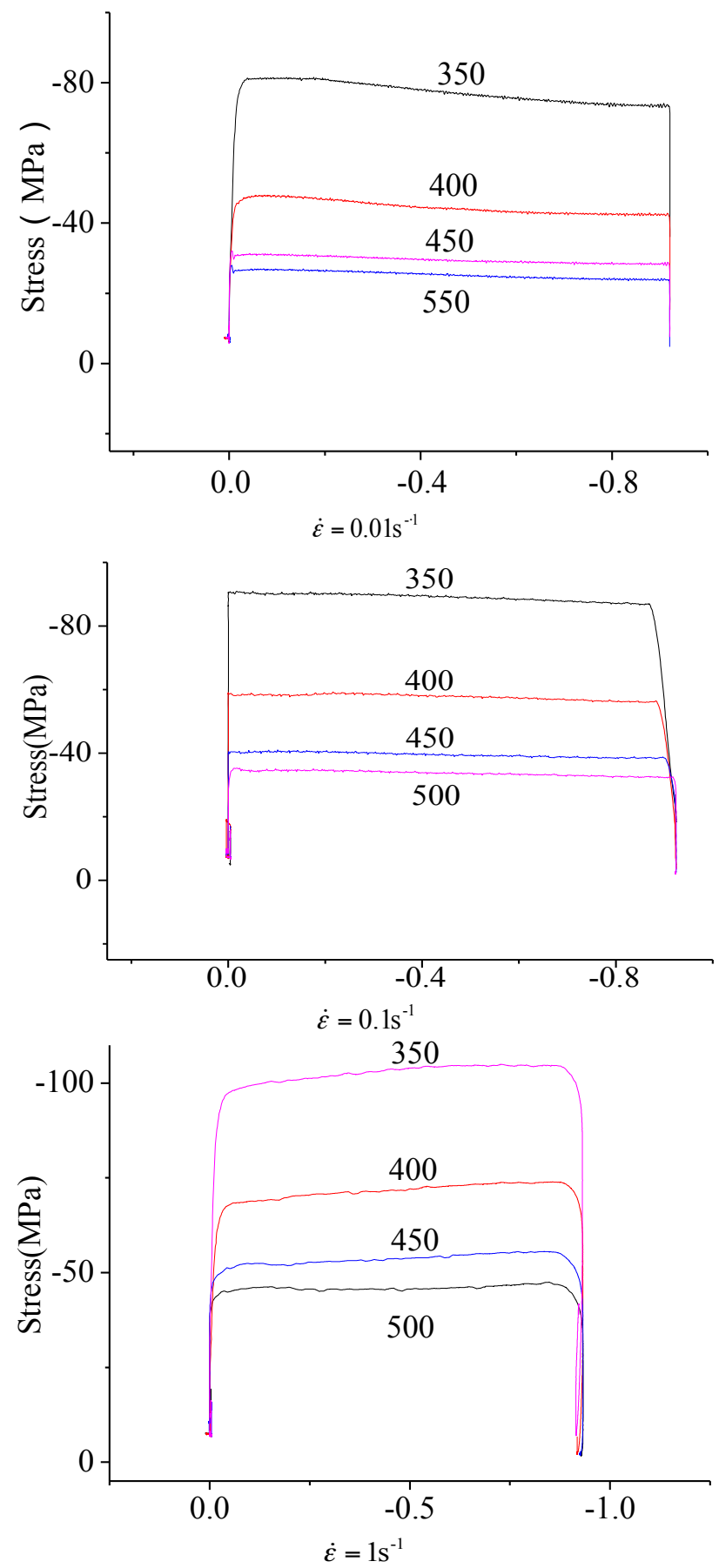

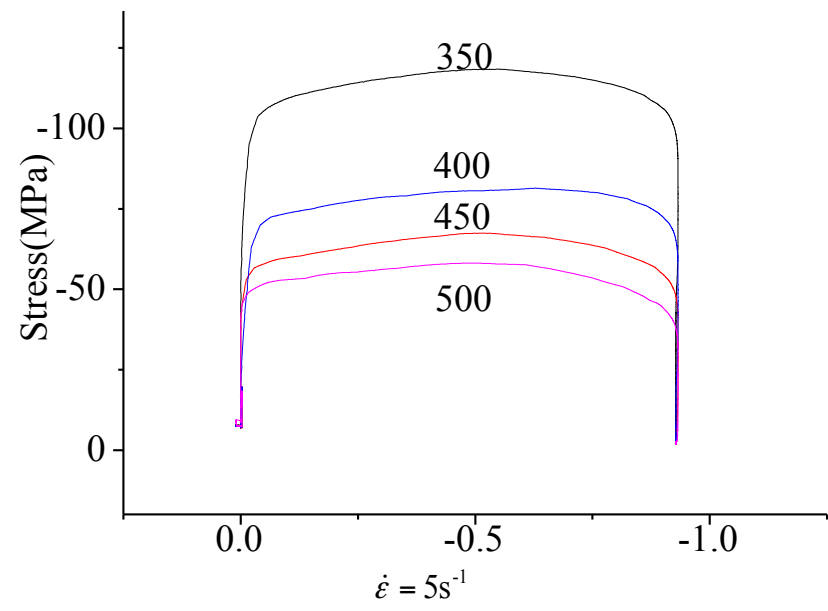

Fig. 4 True stress-strain curves of 6061 aluminum alloy under different deformation temperatures and the same strain rate

Table 2 Stress peaks of 6061 aluminum alloy under different deformation conditions

\begin{tabular}{c|c|c}
\hline $\begin{array}{c}\text { Temperature } \\
{ }^{\circ} \mathbf{C}\end{array}$ & $\begin{array}{c}\text { Strain rates } \\
\boldsymbol{S}^{-1}\end{array}$ & $\begin{array}{c}\text { Stress peaks } \\
\text { MPa }\end{array}$ \\
\hline \multirow{3}{*}{350} & 0.01 & 81.5779 \\
& 0.1 & 90.9572 \\
& 1 & 104.9683 \\
400 & 5 & 118.4161 \\
\hline \multirow{3}{*}{450} & 0.01 & 47.9985 \\
& 0.1 & 59.2316 \\
& 1 & 73.9613 \\
& 5 & 81.4234 \\
\hline \multirow{3}{*}{500} & 0.01 & 32.0335 \\
& 0.1 & 41.0572 \\
& 1 & 55.5812 \\
& 5 & 67.4208 \\
\hline & 0.01 & 27.9795 \\
& 0.1 & 35.2839 \\
& 1 & 47.4713 \\
& 5 & 58.1367 \\
\hline
\end{tabular}

(1) High deformation temperature strengthens the dynamic recovery and recrystallization softening of alloy during the deformation process and decreases rheological stress. The dynamic recovery and recrystallization occur in advance.

(2) The critical shear stress of materials declines with an increase in deformation temperature, thereby increasing the number of slip systems. Accordingly, the rheological stress of aluminum alloy decreases.

(3) High deformation temperature is accompanied by a large thermoplasticity of materials and strong thermal vibration of atoms. The atom instability in a lattice is intensified, thereby decreasing the deformation resistance of metals.

Under a low strain rate $\left(0.01\right.$ or $\left.0.1 s^{-1}\right)$, stress begins to decrease with an increase in strain after the flow stress reaches the peak. At this moment, the softening effect of dynamic recovery is stronger than that of work hardening. The dynamic recovery and work hardening reach a general balance after the flow stress reaches an extreme level given a high strain rate $\left(1\right.$ or $\left.5 s^{-1}\right)$, thus maintaining stress at a fixed value. True stress-strain curves under different small strain rates were compared in this study. The strain is lower than 0.1 when the strain rate is lower than $0.1 s^{-1}$, thereby indicating that it has entered into the steady flow stage. Flow stress slightly decreases in the steady state. The strain increases to 0.3 when the strain rate is higher than $0.1 \mathrm{~s}^{-1}$, 
and the flow stress enters into the steady state. Subsequently, stress remains constant with strain changes.
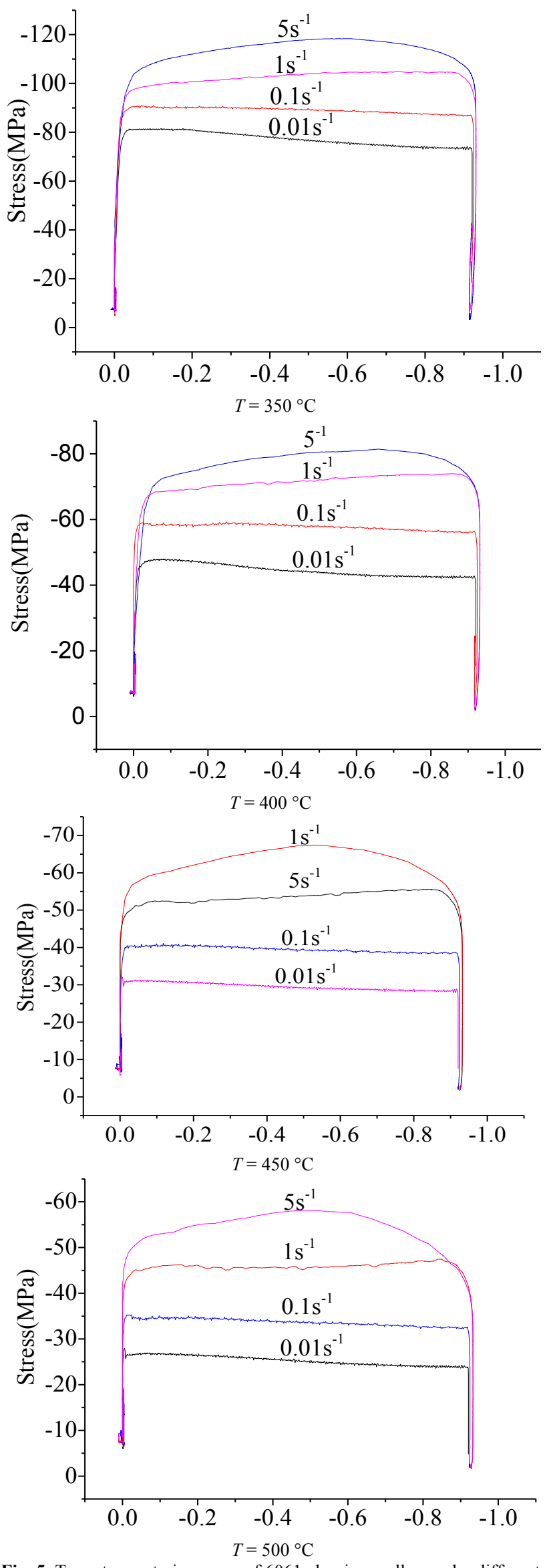

Fig. 5. True stress-strain curves of 6061 aluminum alloy under different strain rates and the same temperature
Fig. 5 shows that true stress is positively related to strain rate given the same deformation temperature. This result indicates that the 6061 aluminum alloy is a material sensitive to a positive strain rate. The plastic deformation of 6061 aluminum alloy is completely undeveloped with the increase of strain rate while the elastic deformation increases, thereby resulting in the growth of flow stress. This condition is mainly caused by the direct influences of dislocation, energy, and strain rate on dynamic recovery and recrystallization.

4.1 Constitutive equation of high-temperature rheological stress of 6061 aluminum alloy

Numerous experts and researchers worldwide have proposed many expressions of constitutive equations. In this study, a model is developed with the popular Arrhenius equation proposed by Sellars and Tegart with consideration of the influences of deformation temperature, volume, and rate on the rheological stress of aluminum alloy materials under plastic deformation.

$\dot{\varepsilon}=A F(\sigma) \exp (-Q / R T)$

where $F(\sigma)$ has the following three expressions:

$F(\sigma)=(\sigma)^{n}$

$F(\sigma)=\exp (\beta \sigma)$

$F(\sigma)=\sinh (\alpha \sigma)^{n}$

where $\sigma$ is the flow stress (MPa); $Q$ is the activated energy of deformation $(\mathrm{kJ} / \mathrm{mol}) ; R$ is the gas constant $(8.31$ $\mathrm{J} /(\mathrm{mol} / \mathrm{K})) ; T$ is the absolute temperature $(\mathrm{K}) ; \dot{\varepsilon}$ is the deformation rate $\left(s^{-1}\right)$; and $A, n, \alpha$, and $\beta$ are the material constants, where the relationship of $n, \alpha$, and $\beta$ is $\alpha=\beta / n$.

The first equation of the power function is applicable to a low stress level $(\alpha \sigma<0.8)$. The second equation of the exponential function is applicable to a high stress level ( $\alpha \sigma$ $>1.2$ ). The third equation of the hyperbolic sine function is applicable to all stress levels. The parameters calculated by the hyperbolic sine function are highly accurate.

Equations (2)-(4) are brought into the Arrhenius equation, that is,

$$
\begin{aligned}
& \dot{\varepsilon}=A \sigma^{n} \exp (-Q / R T), \\
& \dot{\varepsilon}=A \exp (\beta \sigma) \exp (-Q / R T), \\
& \dot{\varepsilon}=A \sinh (\alpha \sigma)^{n} \exp (-Q / R T) .
\end{aligned}
$$

The logarithms are calculated as follows according to the above-mentioned three equations:

$$
\begin{aligned}
& \ln \dot{\varepsilon}=\ln A+n \ln \sigma-Q / R T, \\
& \ln \dot{\varepsilon}=\ln A+\beta \sigma-Q / R T,
\end{aligned}
$$


$\ln \dot{\varepsilon}=\ln A+n \ln \sigma[\sinh (\alpha \sigma)]-Q / R T$.

These three equations are simplified as follows:

$\frac{1}{n} \ln \dot{\varepsilon}=\frac{1}{n} \ln A+\ln \sigma-\frac{1}{n} Q / R T$,

$\frac{1}{\beta} \ln \dot{\varepsilon}=\frac{1}{\beta} \ln A+\sigma-\frac{1}{\beta} Q / R T$,

$\frac{1}{n} \ln \dot{\varepsilon}=\frac{1}{n} \ln A+\ln \sigma[\sinh (\alpha \sigma)]-\frac{1}{n} Q / R T$.

According to Equations (11)-(13), the deformation activation energy $Q$ and gas constant $R$ are constants when the temperature is fixed. Therefore, $1 / n$ is the slope of the straight $\ln \dot{\varepsilon}-\ln \sigma$, and $1 / \beta$ is the slope of the straight $\sigma-\ln \dot{\varepsilon}$.

The scatter diagrams of $\ln \dot{\varepsilon}-\ln \sigma$ and $\sigma-\ln \dot{\varepsilon}$ are drawn with the Origin software on the basis of the data of the thermal compression experiment (Figs. 6 and 7). Then, a linear fitting on scattering points is conducted, and the corresponding straights are fitted. Hence, the slope of the straight is the sum minus the mean, that is, $1 / n$ and $1 / \beta$. Subsequently, the relationship of $n, \alpha$, and $\beta$ is $\alpha=\beta / n$. Therefore, $\alpha$ can be calculated. $n=11.27, \alpha=0.0161$, and $\beta=0.1821$.

As shown in Equation (13), a linear relationship exists between $\ln [\sinh (\alpha \sigma)]$ and $\ln \dot{\varepsilon}$ given the fixed temperature. Scattering points are drawn again with Origin on the basis of the data of the thermal compression experiment and then used in linear fitting (Fig. 8). The slope of the straight is $n$, and the calculated $n$ shows high accuracy. Under this circumstance, $n$ is calculated by the hyperbolic sine functional model and is applicable to full stress level. The mean slope of four straights after linear fitting by Origin is $n$ $=8.11$. When the strain rate is constant, a linear relationship exists between $\ln [\sinh (\alpha \sigma)]$ and $1 / \mathrm{T}$ (Fig. 9). The slope of fitting straight in $\ln [\sinh (\alpha \sigma)]-1000 / \mathrm{T}$ is $Q / R n$, and the gas constant $R$ is $8.314 \mathrm{~J} /(\mathrm{mol} / \mathrm{K})$. The parameters in the constitutive equation are calculated. The result shows that the activation energy is $Q=262.141 \mathrm{~kJ} / \mathrm{mol}$.

As shown in Equation (13), the intercept is $1 / n(Q / R T-$ $\ln A)$ in $\ln [\sinh (\alpha \sigma)]-\ln \dot{\varepsilon}$. According to the parameters of the constitutive equation, $\ln A=42.918, \quad$ and $A=4.36 \times 10^{18}$. Finally, the constitutive equation of hightemperature flow stress of 6061 aluminum alloy is acquired as follows:

$$
\dot{\varepsilon}=A \sinh (0.161 \sigma)^{8.11} \exp \left(-\frac{262.141}{8.314 T}\right)
$$

\subsection{Development of material database}

The main coefficients of the high-temperature constitutive equation of 6061 aluminum alloy are obtained from numerical and regression analyses on the basis of the thermal compression test.

$$
\alpha=0.0161, \beta=0.182, n=8.11, Q=262.141 \mathrm{~kJ} / \mathrm{mol} \text {, }
$$
$\ln A=42.918$, and $A=4.36 \times 10^{18}$.

These data are entered into the finite element simulation software DEFORM for the numerical simulation of thermal deformation. Flow stress in the material base of DEFORM is shown in Fig. 10.

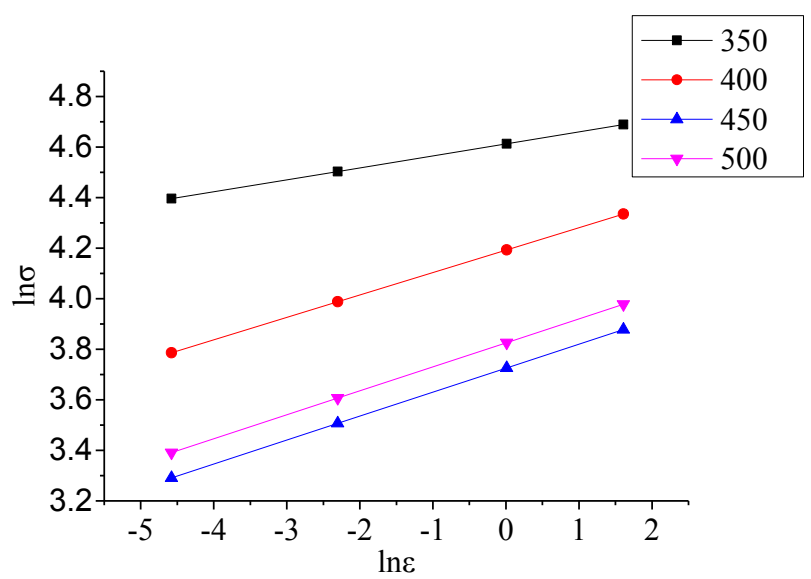

Fig. 6. $\ln \sigma-\ln \dot{\varepsilon}$

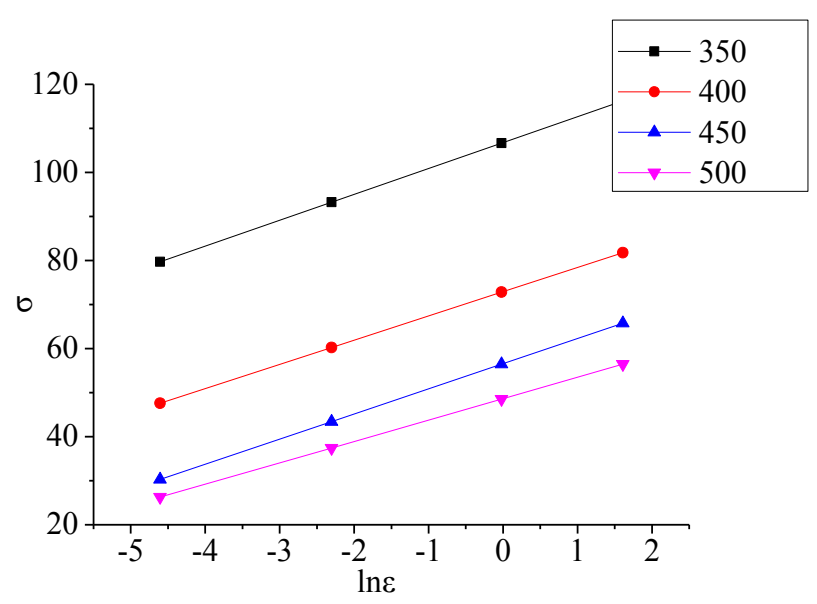

Fig. 7. $\sigma-\ln \dot{\varepsilon}$

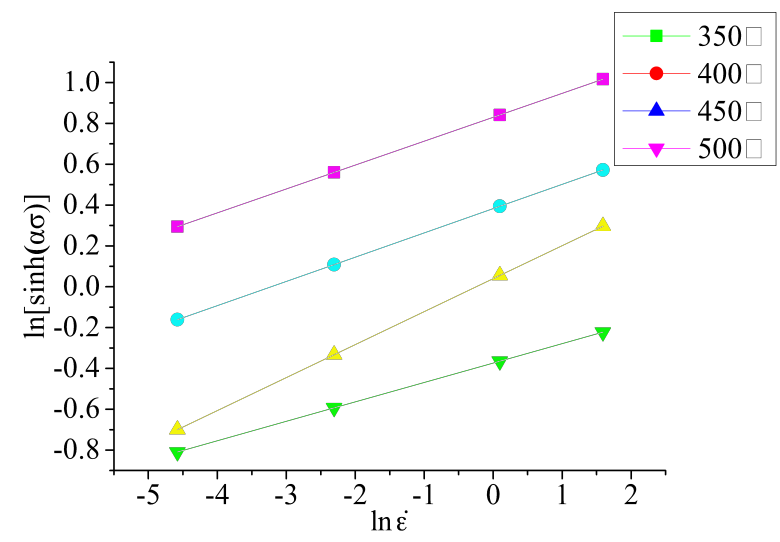

Fig. $8 \ln [\sinh (\alpha \sigma)]-\ln \dot{\varepsilon}$

Relevant data of thermal compression test are entered into the material base of DEFORM. The result is a constitutive equation, which is used for numerical simulation

In program 2, the upper, lower, and lateral punches simultaneously move. Metals are uniform along the flow direction before the deformation, thereby showing stable forging. Metals at the rod mainly flow to the side with more materials. In the beginning, metals mainly flow to the small head and then to the big end. Metals at the big end are mainly used to form two sides of the big end. Only one side 
far from the big end has not been formed when the stroke is about to be ended; the rest is basically formed and achieves an excellent forging effect at the end of the stroke.

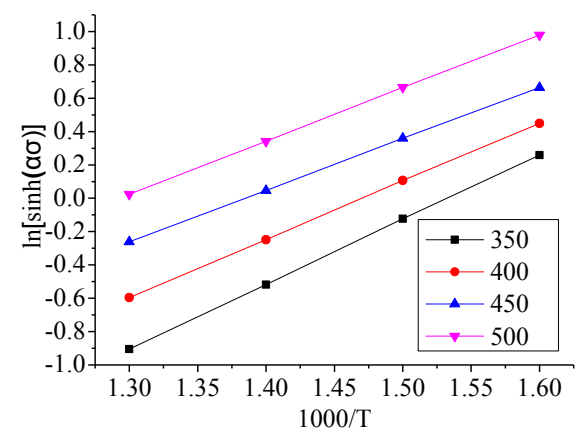

Fig. $9 \ln [\sinh (\alpha \sigma)]-1000 / T$

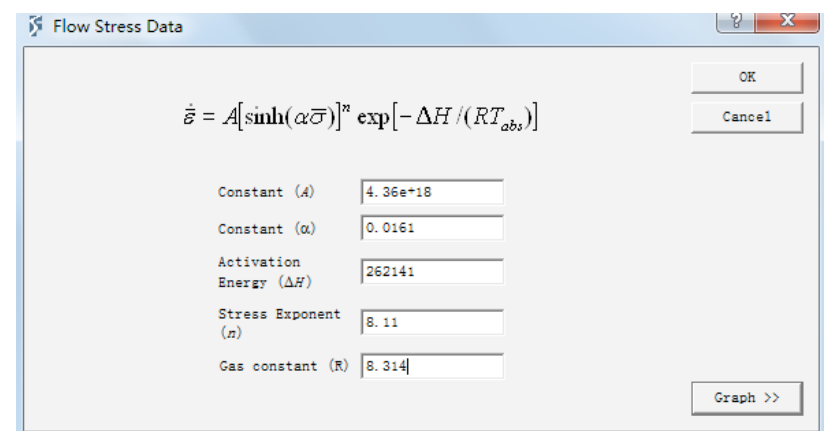

Fig. 10. Flow stress equation

\subsection{Optimization of closed forging program for 6061} aluminum alloy connecting rods

In program 1 described in Section 3.5, the lateral punch first moves while the punches connected to the big head are not filled up. This result is due to a slight surplus of blank metals at the rod body and small head. Moreover, the first movement of the upper punches considerably increases such surplus. When the upper and lower punches move, the rod body and small head are easy to be shaped, but inadequate metals exist in the big end (Fig. 11).

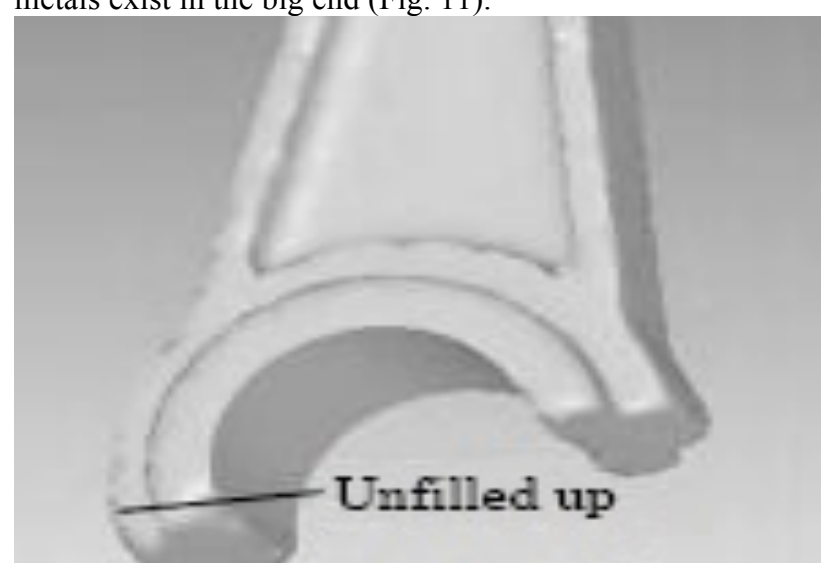

Fig. 11 Unfilled phenomenon

In program 3 , the lateral punch is the last one to move. In the beginning, metals quickly flow to the action direction of the lateral punch. When the lateral punch travels to the half of the stroke, two sides of the big end are mainly formed. Moreover, when the stroke of the lateral punch is about to be ended, one side of the big end of the connecting rod is formed basically and is completely forged at the end of the stroke, with full filling but no wrinkles. The ultimate forging is shown in Fig. 12.

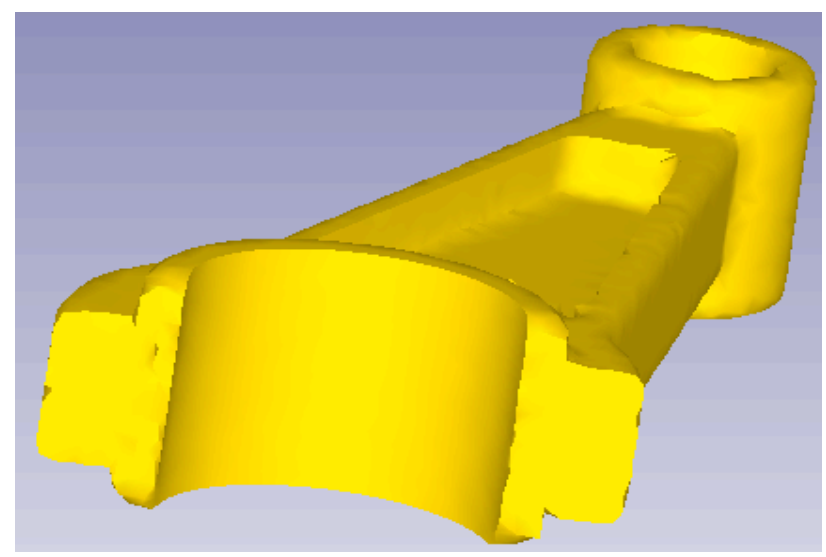

Fig. 12. Ultimate forgings

\subsection{Analysis of forging loads}

The stroke-load curves of the punches are shown in Figs. 13 and 14 . The forging process of aluminum alloy connecting rods is composed of three stages. Stage 1: The upper and lower punches simultaneously move, but the lateral punch remains static. The rod body and small end are formed, and the metal flow is relatively uniform. The loads along the $\mathrm{Z}$ direction of the upper and low punches increase at a steady rate. Stage 2: The upper and low punches stop moving, and the loads considerably drop. Subsequently, the lateral punch begins to move. The big end is mainly formed, and the loads along the $\mathrm{X}$ direction of the lateral punch stably increase. Stage 3: The upper, low, and lateral punches stop moving at the end of the stroke, and the forging process is finished.

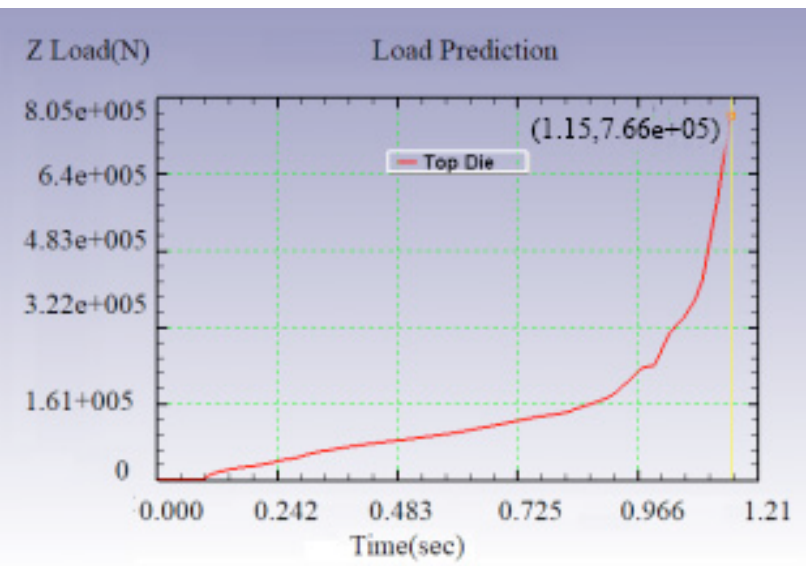

Fig.13. Stroke-load curves along the $X$ direction the lateral punch

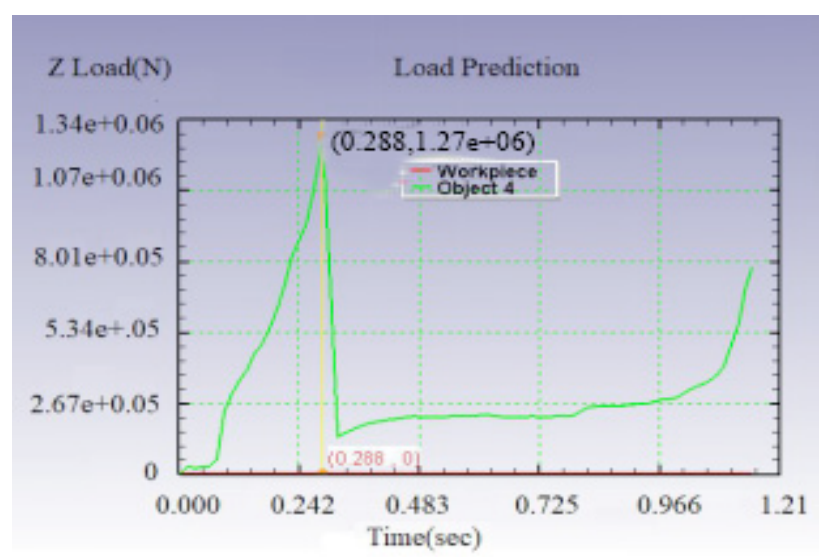

Fig. 14. Stroke-load curve of the upper and lower punches along the $Z$ direction 
As shown in the stroke-load curve of the upper and lower punches, the loads for forging are $F=1.27 e+06 \mathrm{~N}$ (approximately $1300 \mathrm{kN}$ ) when the forging time is $0.3 \mathrm{~s}$, that is, the end of movement of the upper and lower punches. Accordingly, $F=(1.3+2.1) e+06 \mathrm{~N}$ (approximately 340 $\mathrm{kN}$ ) when the forging time is $0.72 \mathrm{~s}$. The forging loads at the end of the movement of the lateral punch is $F=(7.66+8.0) e$ $+05 \mathrm{~N}$, which is approximately $1600 \mathrm{kN}$.

\subsection{Analysis of forging speed field}

The flow simulation results of aluminum alloy connecting rods are shown in Fig. 15. The friction between the mold and the blank is a sticky one, and the friction in various regions acts differently on the blank. During forging, punches force the blank forward. However, the friction between the blank and the mold hinders the blank from moving forward. Therefore, the flow speed field distribution is uneven. In particular, the speed field close to the working belt is larger than those in other regions. According to the law of minimum resistance, metals prefer to flow along an easy path, and the flow speed is small in regions with strong resistance. As illustrated in Fig. 15, the metal flow vectors are basically consistent, which determines excellent forging without overlapping and wrinkles.

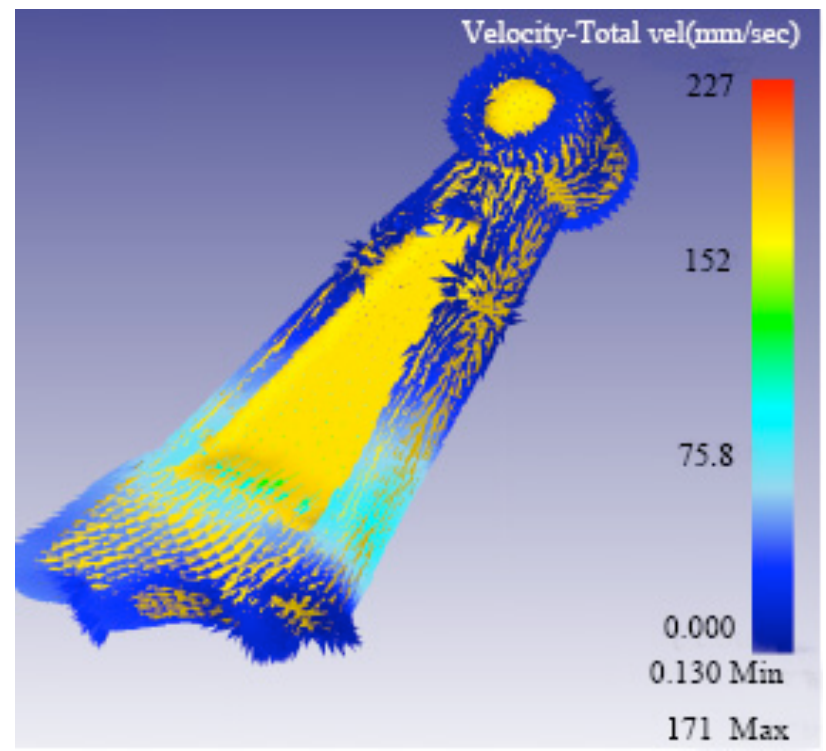

Fig. 15. Flow speed field of materials

\subsection{Equivalent stress-strain analysis of forging}

The equivalent stress and strain at the end of forging are shown in Figs. 16 and 17. Evidently, metals quickly flow to the lateral punch in the beginning, thereby resulting in a large strain. As the lateral punch comes into contact with the blank, the stress at the contact region of the blank and lower mold is greater than that on the upper surface. The most violent changes of stress are observed at the contact region between the blank surface and the lateral punch. The maximum stress is at the compressed part of the blank. The stress on the entire connecting rod is relatively uniform and lower than $320 \mathrm{MPa}$ at the end of forging, which is within the safety range. The maximum equivalent stress occurs at the big head of the connecting rod, thereby indicating the intensifying deformation of the region. The equivalent stress of the entire connecting rod is basically consistent at the end of deformation, and the connecting rod stops producing deformation.

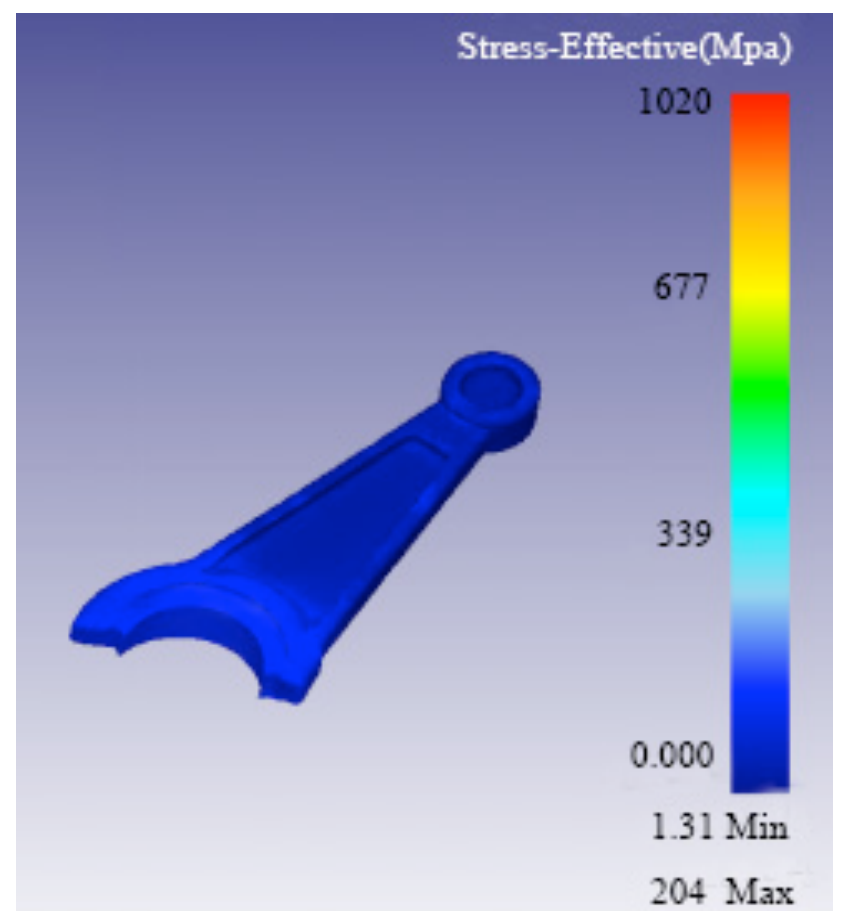

Fig. 16. Equivalent stress

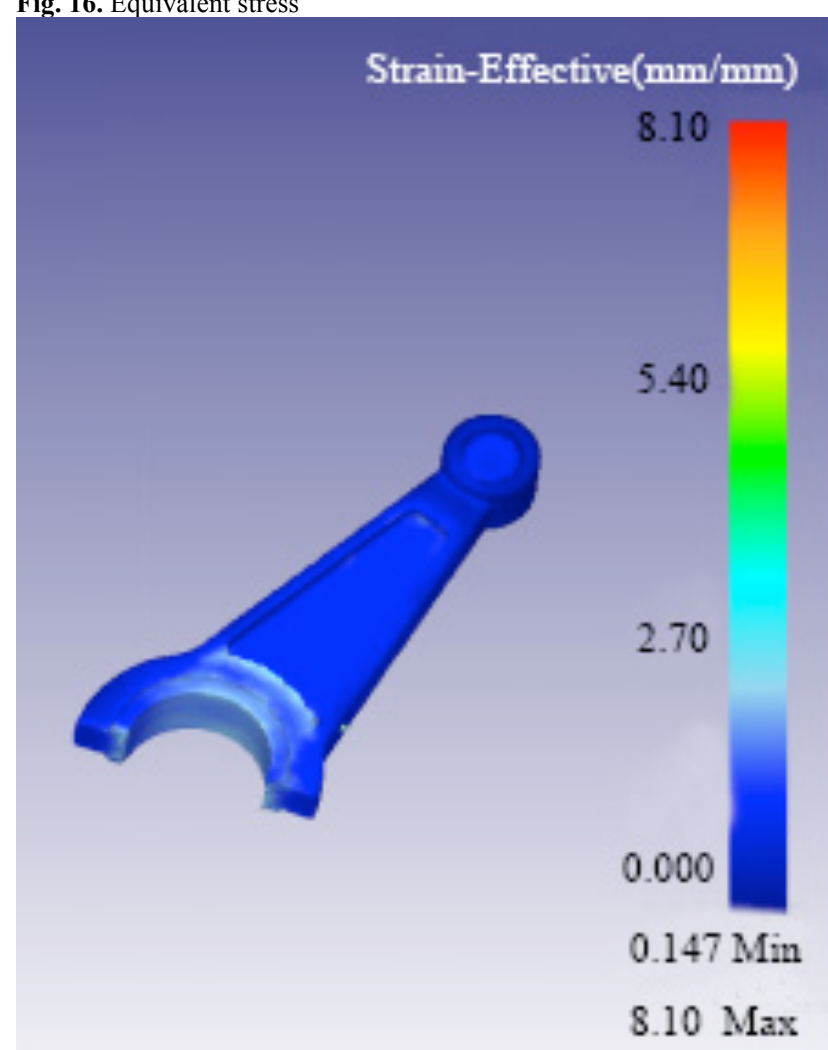

Fig. 17. Equivalent strain

\section{Conclusions}

A finite element model of the closed forging of aluminum alloy connecting rods was developed in this study to explore the closed forging law and relationship of high-temperature rheological behavior and forging quality of aluminum alloy. The high-temperature rheological behavior of 6061 aluminum alloy was discussed by combining the experimental study and numerical simulation. The constitutive equation of high-temperature rheological behavior was derived. Finally, the closed forging process of 
aluminum alloy connecting rods was simulated by numerical simulation software. The following conclusions could be drawn.

(1) The 6061 aluminum alloy is a material sensitive to a positive strain rate. The steady-state flow stress is inversely proportional to temperature given a fixed strain rate. Flow stress is proportional to strain rate given the fixed deformation temperature.

(2) The aluminum alloy connecting rod is in a threedirectional compressive stress state during closed forging. The movement mode of the lateral punch influences forging quality. Forging quality is inversely proportional to the movement order of the lateral punch.

(3) Under a fixed deformation rate and deformation mode, the forging loads of aluminum alloy connecting rods increase first, then decrease, and finally increase. Forging load is proportional to deformation speed.

In this study, a new closed forging technique for aluminum alloy connecting rods was proposed by combining laboratory tests and numerical simulation. The developed constitutive equation of the high-temperature rheological stress of 6061 aluminum alloy is close to that used in practice, and the proposed technological program is reasonable. Research conclusions provide certain references to the development of the precise forging of aluminum alloy connecting rods. As a result of the lack of real data on field production, future studies should combine real forgings and simulation results and correct them accordingly to enrich the understanding of the law of closed forging of aluminum alloy connecting rods.

\section{Acknowledgements}

The study was supported by the Scientific Research Program of the Department of Education of Hei Longjiang Province (Grant No. 12521124).

This is an Open Access article distributed under the terms of the Creative Commons Attribution License
1.Liu J. A.,Zhang H.W.,Xie S. S.,"Aluminum alloy forging technology ". Beijing:Metallurgical Industry Press, China,2012.pp.45-54.

2. Yang X.,Peng Q.,Sun Z. P.,et al.,"Evolution of Microstructure and Tensile Properties of 6061Aluminum Alloy during Muti-directional Forging".Materials for mechanical Engineering,42(7),2008,pp.7377.

3. Ling M. E.,"Development of Isothermal Hot Extrusion Behavior and Optimization of Process Parameters for 6061 Aluminum Alloy".Master thesis of Lanzhou University of Technology,China,2010,pp.8-15.

4. Wu T. B., Ma B., Zhang J. J.,"Numercial Simulation of the Closed Die Forging Process for Aluminum Alloy Connecting Rod". SpecialCasting\&Nonferrous Alloy,35(9),2015,pp.991-994.

5. Zhao P. F., Reng G. S., Sheng Z.,et al.," Influence of Hot Compressive Deformation Conditions of 6061 Aluminum Alloy on Flow Stress and Research on its Constitutive Equation". Journal of Plasticity Engeering,14(6),2007,pp.130-133.

6. Li F. J.,Zhai Y. W.,Bian Q,et al.,"Study of Plastic Deformation behavior on 6061 Aluminum Alloy".Journal of Plasticity Engeering,22(2),2015,pp.95-97.

7. Zhao Z., Bai X. J., Hu C. L.,"Status and Development Trend of Precision Forging Technology".Forging \&Stamping Technology, 43(7), 2018,pp.90-94.

8. Ma B., "Numerical Analysis and Experimental Research on Forming Process of 6061 Aluminum Alloy Connecting Rod Closed-die Forging".Master thesis of Chong Qing University, China,2009,pp.45-48.

9. Zhang J. J. ,"Development Research on Multi-way Precision Forging Technology of High Strength Aluminum Alloy Connecting Rod for Mini-type Gasoline Engine".Master thesis of ChongQing of Technology, China,2009,pp.15-28.

10. Zhang C. M.,"Study on Die-forging Technology of the Aluminum Alloy Connecting Rod".Machinery Design \& Manufacture. (11), 2008,pp.105-106.

11. Wu T. B.,Ma B.,Tang W. B.,et al.,"Effects of Shape and Size of Preform and Forming method on Closed Die Forging Process for Aluminum Alloy Connecting Rod".Hot Working Technology, 45(1), 2015,pp.169-172.

12. Qu J. J.,"The Study of the Closed Die Forging Process of Aluminum Alloy Connecting Rod".Master thesis of ChongQing University, China, 2015, pp.32-40.

13. Yao B.,Fang G. ,"Numerical Simulation of Pre-forging for Connecting Rod of Aotumobile Engine and Optimization of Its Preforging Billet”. Casting\&Forging\&Welding,(7),2009,pp.106-109.

\section{eferences}

14. Huang S. P.,"Study on the Multiple Forging Process and Microstructure Evolution of 6061Aluminum Alloy".Master thesis of GuangXi University, China,2017,pp.21-34.

15. Rao P. N., Singh D., Jayaganthan R.,"Mechanical properties and microstructural evolution Al 6061 alloy processed by multidirectional forging at liquid nitrogen temperature". Materials \& Design (1980-2015),56(4) ,2014,pp.97- 104.

16. Cherukuri B., Nedkova T. S., Srinivasan R.,"Comparison of the Properties of SPD-Processed AA-6061 by Equal-channel Angular Pressing, Multi-axial Compressions/Forgings and Accumulative Roll Bonding”. Materials Science \& Engineering:A,410411,2005,pp.394-397.

17. Zhou M., Clode M.P.,"Constitutive Equations for Modeling Flow Softening due to Dynamic Recovery and Heat Generation during Plastic Deformation".Mechanics of Materials,27,1998,pp.63-76.

18. Sitdikov O., Sakai T., Goloborodko A., et al. ,"Effect of Pass Strain on Grain Refinement in7475 Al Alloy during Hot Multidirectional Forging”. Materials Transactions,45(7),2004,pp.2232-2238.

19. Khaleed H. M. T., Samad Z., Othman A. R.,"Computer-Aided FE Simulation for Flashless Cold Forging of Connecting Rod Without Underfilling".Arab Journal of Science Engineering,36,2011,pp.855-865.

20. Zhao H., Liu G. Q., Xu L.,"Rate-controlling Mechanisms of Hot Deformation in a medium carbon vanadium microalloy steel". Materials Science and Engineering: A, 559,2013,pp. 262-267.

21. Chen S., Chen K., Peng G., et al., "Effect of heat treatment on hot deformation behavior and microstructure evolution of 7085 aluminum alloy ".Journal of Alloys and Compounds, 537, 2012, pp. $338-345$.

22. Liu Y. H., Wang J.,Wang D. H.,"Numerical Optimization on Hot Forging Process of Connecting Rods based on RSA with Experimental Verification".International Journal of Advaced Manufuring Technology, 90 , 2017,pp.3129-3135.

23.Jia Z., Ji J. J.,"Influence analysis of shot peening on hot forging die". International Journal of Advaced Manufuring Technology, 90(5-8), 2017, pp.1779-1787.

24.Bariani. P.F., Bruschi S.,"Modelling the Forging and Post-forging Cooling of C70S6 Conrods". Journal of Materials Processing Technology, 167(2-3),2005, pp.529-535.

25. Knust J., Stonis M.,Behrens B.A."Preform optimization for hot forging processes using an adaptive amount of flash based on the cross section shape complexity". Production Engeering, 10(6),2016,pp.587-598. 